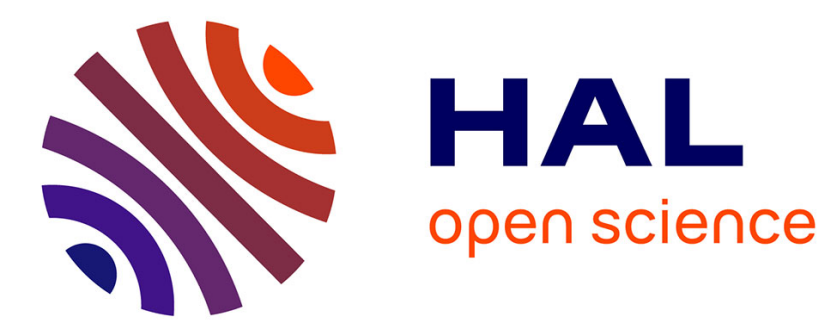

\title{
Experimental methods at high rates of strain
}

\author{
John Field, S. Walley, N. Bourne, J. Huntley
}

\section{To cite this version:}

John Field, S. Walley, N. Bourne, J. Huntley. Experimental methods at high rates of strain. Journal de Physique IV Proceedings, 1994, 04 (C8), pp.C8-3-C8-22. 10.1051/jp4:1994801 . jpa-00253331

\section{HAL Id: jpa-00253331 https://hal.science/jpa-00253331}

Submitted on 1 Jan 1994

HAL is a multi-disciplinary open access archive for the deposit and dissemination of scientific research documents, whether they are published or not. The documents may come from teaching and research institutions in France or abroad, or from public or private research centers.
L'archive ouverte pluridisciplinaire HAL, est destinée au dépôt et à la diffusion de documents scientifiques de niveau recherche, publiés ou non, émanant des établissements d'enseignement et de recherche français ou étrangers, des laboratoires publics ou privés. 
JOURNAL DE PHYSIQUE IV

Colloque C8, supplément au Journal de Physique III, Volume 4, septembre 1994

\title{
Experimental methods at high rates of strain
}

\author{
J.E. Field, S.M. Walley, N.K. Bourne and J.M. Huntley \\ Cavendish Laboratory, Madingley Road, Cambridge CB3 OHE, U.K.
}

\begin{abstract}
Résumé. Le domaine de recherche qui est le sujet de la revue présente est à la fois vaste et importante, et il est impossible de lui entièrement rendre justice dans le cadre de cet article. Néanmoins, nous tentons ici de tracer l'histoire de quelques-uns des développements les plus importants et d'inclure la plupart des techniques majeures. En particulier, nous traitons en détail les sujets suivants: essai de choc de Taylor, test de barre de Hopkinson, et essai d'impact de plaque 1-D. Et finalement, nous discutons le progrès récent en photographie ultrarapide domaine-clef, en particuliers en association avec des techniques optiques.
\end{abstract}

\begin{abstract}
The subject area covered by this review is a large and important one and to do it full justice would require a larger format than is available here. However, an attempt is made to outline the history of some of the more important developments and to include most major techniques. Taylor impact, Hopkinson bar testing in its various forms and 1-D plate impact are all considered in some detail. High-speed photography, particularly when used in association with optical techniques, is a key area and recent advances are discussed.
\end{abstract}

\section{Historical Foundations OF High STRAIN-RATE TESTING}

As the 19th century progressed, there was an increasing awareness that the properties of materials under impact differed from those under static or 'dead' loading [1-5]. Experimental investigations were hampered by lack of suitable intrumentation, but considerable theoretical progress was made in the understanding of the propagation of stress waves in bounded media such as circular rods [6-9]. It is generally considered that J. Hopkinson in 1872 made the first experimental demonstration that metals can withstand a larger impulsive load in simple tension than they can under static loading $[2,3]$. His son $\mathbf{B}$. Hopkinson carried out further work in this area [10] and also invented an ingenious ballistic pendulum method for determining the shapes of pulses caused by the impact of bullets or the detonation of explosive charges at one end of a long rod [11]. By using momentum traps of different lengths, he was able to build up a picture of how much momentum passed down the rod as a function of time for different classes of event (assuming that these types of event are repeatable). Because he performed the pioneering work on determining the shapes of impulses travelling down rods, the device consisting of a long rod to convey a force pulse to a force transducer became known as the Hopkinson pressure bar. These achievements of the Hopkinsons were reviewed by G.I. Taylor in a lecture he gave in 1946 [12].

With the development of the continuous strip mill in the 1920 s there was renewed interest in determining the dynamic properties of steels both in tension and in torsion, particularly at high temperatures [13-31]. Very little work seems to have been performed on dynamic compressive loading before the Second World War, though G.I. Taylor had been thinking of a method of estimating the dynamic strength of materials in compression towards the end of the 1930s [12]. His method consists of firing a solid cylinder of the material against a massive and rigid target. The dynamic flow stress of the cylinder material can be estimated by measuring the overall length of the impacted cylinder and the length of the undeformed (rear) section of the projectile $[32,33]$ by means of the following simple formula: 


$$
\sigma=\frac{\rho V^{2}(L-X)}{2(L-L) \ln (L / X)}
$$

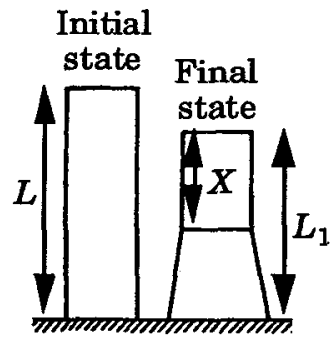

Figure 1. Schematic diagram of initial and final states of a Taylor impact specimen (from ref. [32])

where $\sigma$ is the dynamic yield stress of the material of the projectile, $\rho$ its density, $V$ its impact velocity, and $L, X$ and $L_{1}$ are defined in figure 1 .

One of the assumptions made in deriving this expression was that the rear of the projectile undergoes constant deceleration. Taylor $\&$ Whiffin knew that this assumption is not true, but an analysis taking account of the variation in acceleration yields a set of expressions that are transcendental in the yield stress and in which the plastic wave speed acts as a free variable. Taylor and Whiffin's method of solving these equations consisted of numerically determining the plastic wave speed consistent with both the measured deformation and their theory. This then allowed the yield stress to be determined. In order to use this more exact method routinely, Taylor presented it as a set of graphs yielding multiplicative correction factors to equation (1). Whiffin showed that the correction factor was velocity dependent, being $c a$. 1.12 at about $100 \mathrm{~m} \mathrm{~s}^{-1}$ and $c a .1 .06$ at about $800 \mathrm{~m} \mathrm{~s}^{-1}$ for mild steel cylinders.

The publication of this method occurred just before Kolsky's famous paper on the use of two Hopkinson pressure bars to measure the dynamic properties of materials in compression [34]. This device became known as the split Hopkinson pressure bar (SHPB) and soon became the standard technique for obtaining such properties, having the advantages over the Taylor test of loading the material under nearly uniform stress and strain rate. To date, there are about 800 papers in the literature on SHPB testing of metals, 150 on polymers, and a handful on ceramics and rocks.

However, the Taylor test, or variants on it, has been used and developed to the present day (there are about 100 papers in the literature on this topic), not often for obtaining dynamic yield stresses of materials but for studying (a) the propagation of plastic waves, e.g. [35-40] and (b) for checking constitutive models by comparing the shapes of recovered cylinders with computer predictions, e.g. [41-52]. It has also been used for its original purpose in obtaining the dynamic properties of polymers at room temperature [53,54] and metals at elevated temperatures [55-57]. Other methods for obtaining dynamic stress-strain curves in compression that have been developed include the cam plastometer [58] and techniques where the specimen is loaded either by dropping a weight on it $[59,60]$ or by firing a mass against it $[61,62]$. These methods produce somewhat lower strain rates than the SHPB: $10^{2} \mathrm{~s}^{-1}$ as opposed to $10^{3} \mathrm{~s}^{-1}$. A summary of the major developments in high strain rate testing up to the invention of the SHPB is given in Table 1.

TABLE 1

\begin{tabular}{lll} 
& \multicolumn{1}{c}{ Developments in high strain-rate testing (excluding shock wave studies) } \\
Date & Major developments & Reference \\
1807 & Elastic waves in solids and fracture strength & {$[1]$} \\
$1800 \mathrm{~s}$ & Interest in dynamic fracture strength of rail steel & {$[4]$} \\
1872 & Dynamic loading of wires & {$[2,3]$} \\
1876 & Dispersion of elastic waves in rods & {$[6]$} \\
1883 & Elastic waves in impacted rods & {$[8]$} \\
1889 & Dispersion of elastic waves in rods & {$[10]$} \\
1905 & Rapid loading of metals & {$[11]$} \\
1914 & Determination of pulse shapes due to bullet impact and explosions using & {$[13-31]$} \\
$1920 \mathrm{~s}-$ & Interest in impact loading of steels in tension and torsion at high & \\
$1930 \mathrm{~s}$ & temperatures due to the development of the strip mill & {$[63-69]$} \\
$1940 \mathrm{~s}-$ & Use of long rods as mechanical wave guides in & {$[61,62,70]$} \\
$1950 \mathrm{~s}$ & various applications & {$[12,32,33,71]$} \\
$1940 \mathrm{~s}$ & Early attempts at compressive dynamic loading & {$[27,72]$} \\
$1940 \mathrm{~s}$ & Taylor test developed & \\
$1940 \mathrm{~s}$ & Early use of strain gauges in dynamic testing &
\end{tabular}


1948 Davies analyses the propagation of waves in the Hopkinson pressure bar and develops an electrical capacitance method for measuring stress pulses in rods

1949 Kolsky develops the SHPB

1950 Development of the cam plastometer

1950s Experimental checks of the St Venant hypothesis and hence legitimation of the use of surface strain gauges to measure stress pulse propagation

\section{DEVELOPMENT OF THE SPLIT HOPKINSON PRESSURE BAR (SHPB)}

The development of Hopkinson's pressure bar into a transducer for measuring the dynamic properties of materials depended on several factors, perhaps the most important being the design and construction of electronic amplifiers with sufficient bandwidth to amplify signals with $\mathrm{MHz}$ frequency components without significant distortion [34]. There had also been renewed interest in the problem of the dispersion of elastic waves travelling down solid rods during the early $1940 \mathrm{~s}$ as it was desired to use them as mechanical waveguides in various applications, e.g. [63, 65, 68, 69]. Following Davies [73], Kolsky used a condenser microphone method to detect pulses in his pressure bar [34], though wire strain gauges had already been used in impact tension test machines $[27,72]$.

There was some concern whether a strain pulse measured by a gauge on the surface of a bar was representative of the wave travelling down its interior $[75,78]$, particularly if the specimen were to have a diameter significantly different to the pressure bar $[74,76]$. For this reason and also because they were concerned about longitudinal inertial effects, early workers used thin wafers of materials with a diameter only just less than that of the bars (aspect ratios of $c a .10)[34,79,80]$ or alternatively they studied plastic wave propagation down long bars, e.g. [40, 81-85].

There are problems associated with obtaining stress-strain curves from wave propagation data in that assumptions have to be made about the material response in advance of actually measuring it [86] and the wave profiles are not very sensitive to the form of the constitutive equation [87]. But the use of thin wafers also has disadvantages in that the frictional stresses and radial inertia are commensurable with the strain rate effect [86], materials can only be tested that have a lower yield stress than the bar [88,89], and the strain that can be imposed is small [83]. However, the work of Davies \& Hunter [86] and Lindholm [90] opened the way to use specimens with smaller aspect ratios (ca. 1). Strain gauges started to be used in SHPBs in the mid 1950 s to early 1960 s $[79,90-92]$. These have the advantage over capacitance methods in that their signals do not require differentiation to obtain particle velocities [79] but the disadvantage that they cannot average the strain over the whole section of the bar.

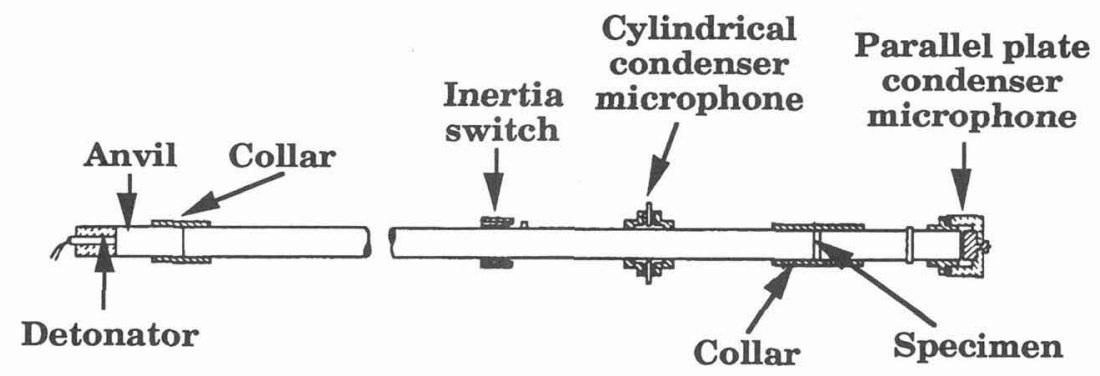

Figure 2. Schematic diagram of original SHPB (from ref. [34])

In order to calculate a stress-strain curve for a cylindrical specimen deforming between the two instrumented bars, it is necessary to know the displacements of the ends of the specimen and the forces acting on these ends. A simple one-dimensional wave analysis, whose derivation may be found in a number of places, e.g. [34, 90, 93, 94], shows that if the forces on the two ends of the specimen are equal, then

$$
\begin{gathered}
\dot{\varepsilon}(t)=-\frac{2 c_{\mathrm{b}}}{l_{\mathrm{s}}} \varepsilon_{\mathrm{R}}(t), \\
\sigma(t)=\frac{c_{\mathrm{b}} Z_{\mathrm{b}}}{A_{\mathrm{s}}} \varepsilon_{\mathrm{T}}(t),
\end{gathered}
$$


where $\dot{\varepsilon}$ is the strain rate and $\sigma$ is the stress in the specimen, $c_{\mathrm{b}}$ is the elastic wave speed and $Z_{\mathrm{b}}$ the mechanical impedance of the bar material (usually identical bars are used), $\varepsilon_{R}$ is the strain wave in the input bar caused by reflection from the specimen, $\varepsilon_{\mathrm{T}}$ is the strain wave in the output bar caused by transmission through the specimen, and $l_{\mathrm{s}}$ is the instantaneous length and $A_{\mathrm{s}}$ is the instantaneous crosssectional area of the specimen. Knowing the time taken for elastic waves to travel from the specimen to the gauges on the input and output bars, the reflected and transmitted pulses can be time-shifted to coincide at the specimen. Then by integrating equation (2) (making use of the definition that $\varepsilon=\ln \left(l_{0} / l_{\mathrm{s}}\right)$, where $l_{0}$ is the initial length of the specimen) we can find $\varepsilon(t)$ and $l_{\mathrm{s}}(t)$. Assuming the volume of the specimen does not change during the deformation, this information gives $A_{s}(t)$ and hence $\sigma(t)$ from equation (3). The stress-strain curve can then be constructed by eliminating time as a variable.

A number of problems with this procedure have been identified over the years. First, do the forces at the ends of the specimen become equal, and if they do, how long does this take [95-99]? Second, might the details of the strain-rate history during the loading phase affect the microstructural state of the material and hence the measured flow stress [100-103]? Third, because many high strain-rate applications require stress-strain curves to be known out to large strains, the original specimen diameter must be significantly smaller than the pressure bar diameter (this allows a large deformation to be imposed before the specimen diameter equals the bar diameter and equations (2) and (3) become invalid). This means in turn that the elastic wave pulse close to the bar end is not one-dimensional as assumed in the above analysis. The question thus arises as to whether the pulse becomes planar, and if does how far from the bar ends should the surface strain gauges be placed $[89,104-106]$ ? Fourth, how much error in the stress-strain curve is introduced by assuming the measured strain pulses can be time-shifted back to the specimen position when in fact these pulses are distorted by wave dispersion effects as they travel down the bars and can this be corrected for [107-112]? Fifth, how much effect do (i) friction between the specimen and bar ends and (ii) radial inertia have on the assumption that the stress in the specimen is uniaxial and can these two effects be allowed for or made negligible [86, 98, 113-115]?

The main driving force behind the development of the technique has been the need to obtain numerical values for the parameters of the various constitutive models used in the numerical modelling of various impact geometries. Thus SHPBs have not only been constructed to load specimens in uniaxial compression but also in uniaxial tension [116], torsion [117], and simultaneous torsion-compression [118]. SHPBs have also been used to load notched specimens either to measure shear strength [119-121] or fracture toughness, e.g. [122-124]. With brittle or low strength materials, failure may occur during the initial loading ramp, so such specimens often have gauges attached directly to them, e.g. $[125,126]$.

Temperature has proportionately a much greater effect on material strength than strain rate. But though its effects on high strain-rate deformation have long been studied (see the references listed in Table 1 ), it has not been given recently the attention it deserves. Some work has, however, been performed on temperature effects using SHPBs, e.g. [92, 93, 127-131], as well as other types of machines, e.g. dropweight towers [59,60,132], cam plastometers [133] and hydraulic testing machines [134]. The existence of temperature gradients in the input and output bars potentially introduces further distortion into the measured signals, e.g. [92, 135-137], but some authors have found this effect to be small [138, 139]. It can be compensated for by tapering the bars to maintain the mechanical impedance constant along their length [129].

Temperature effects come into the problem another way in that high strain-rate deformation results in work being dissipated as heat faster than it can flow away [140]. Thus the temperature of a rapidly deforming specimen rises, sometimes by many hundreds of degrees [141-145]. This can lead to mechanical instability and the localization of deformation into very narrow sheets of material, so called 'adiabatic shear bands' (for recent overviews of this topic, see refs. [146, 147]). This temperature rise has to be taken into account when checking constitutive models, for strictly speaking, comparisons of the strength of a material at different strain rates are only valid if the material is in the same state [148]. For this reason some authors have sought to allow for the temperature rise and compute isothermal high strainrate stress-strain curves [145, 149,150].

The widely reported upturn in flow stress at strain rates in excess of $10^{4} \mathrm{~s}^{-1}$ (often explained in terms of viscous drag on dislocations [151-154]) has been called into question recently for a number of reasons. First, the upturn looks to occur at a strain rate suspiciously close to that where radial inertial stresses start to increase rapidly (compare figures (3) and (4)). 


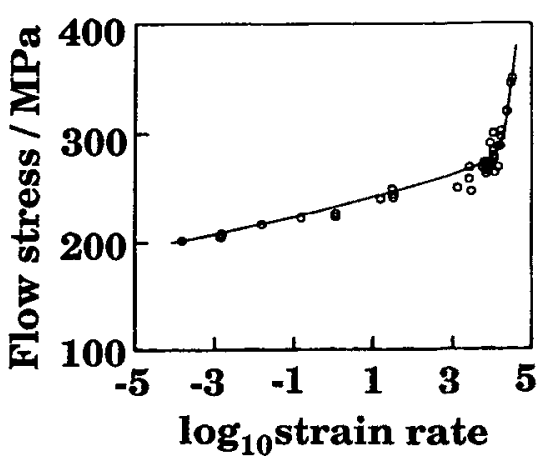

Figure 3. Flow stress of annealed 0.9999 copper at a strain of 0.15 as a function of strain rate (from ref. [153])

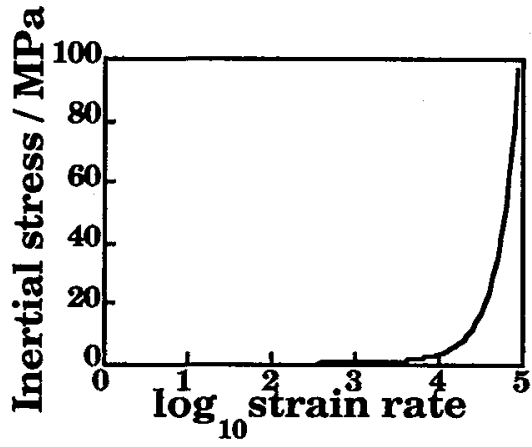

Figure 4. Inertial stress as a function of strain rate calculated using the formula given in [155] for copper specimens $3.8 \mathrm{~mm}$ in diameter and $2.3 \mathrm{~mm}$ thick (the smallest specimen size used in ref. [153]).

A criterion computed by Bertholf \& Karnes [97] shows that for an SHPB compression test to be valid, the following inequality must hold: $D \dot{\varepsilon}_{\max } \leq 50 \mathrm{~m} \mathrm{~s}^{-1}$ where $D$ is the bar diameter. Gorham has returned to this matter recently and found that for copper the radial inertial stress would be half the flow stress if $d \dot{\varepsilon} \approx 42 \mathrm{~m} \mathrm{~s}^{-1}$ where $d$ is the specimen diameter [155]. He points out that several authors have tested specimens with dimensions too large for the strain rates they were working at. One way legitimately to obtain very high strain rates in compression is to use a small SHPB as suggested by Lindholm [156]. However, the increase in rate sensitivity at very high strain rates has also been observed in torsional experiments where radial inertia plays no role, e.g. [157].

Second, flow stresses at different strain rates have usually been compared at equal strains, and strictly speaking this is invalid as strain is not a state variable [158]. This is because the microstructure, which is a true state variable, may depend on the loading path which brought the specimen to that strain [159-161] (e.g. twinning is observed in iron at high strain rates but not at low strain rates $[157,162,163]$ ). However, since it is not usually possible to characterise the microstructural state during deformation, much effort has gone into finding a mechanical state variable that is measurable $[103,111,164,165]$. Following on from work performed at low strain rates, there has been some work done on determining how much effect strain and strain-rate history have on mechanical properties by means of strain-rate change tests where part of the loading history occurred at high rates of deformation, e.g.[101, 102, 139, 161, 166].

Third, recent modelling work by Dioh and colleagues has shown that the upturn may be due to the specimen never reaching stress equilibrium due to the slow speed of propagation of plastic waves [167]. However, their work indicates that a downturn in stress is just as likely as an upturn.

Radial inertia sets a limit to the strain rate that can be achieved by compression testing under uniaxial stress conditions. For in order to achieve a strain rate of $10^{5} \mathrm{~s}^{-1}$ and keep inertial stresses negligible the specimen diameter must be less than about $0.5 \mathrm{~mm}$. Specimens this small will not have mechanical properties representative of the bulk unless they are amorphous or at least almost nanocrystalline [168]. Conventional SHPBs, with bar diameters of $10 \mathrm{~mm}$ or larger, are not suitable for testing such very small specimens. Also dispersion causes the rise time of the loading pulse to increase as the wave travels down the input bar, lowering the strain rate achieved. Because the speed of propagation of a given frequency component depends on the amount of radial motion associated with that frequency, bars made from a material with a low Poisson's ratio would produce little dispersion, but suitable materials (e.g. beryllium with a Poisson's ratio of 0.05 ) are either too brittle or poisonous [169].

A number of workers suggested that another way around this problem of dispersion was to dispense with the input bar and impact the specimen directly [170-172]. However, Wulf \& Richardson's claim to have achieved strain rates of $10^{5} \mathrm{~s}^{-1}$ is probably doubtful as they used bars $12.5 \mathrm{~mm}$ in diameter. Direct impact Hopkinson pressure bars of these kind of dimensions have subsequently been used to obtain the dynamic fracture properties [173, 174] and compressive strength [175] of propellants and polymers [114, 176] at more modest strain rates $\left(10^{3} \mathrm{~s}^{-1}\right)$. Direct tension Hopkinson bars have also been constructed [177].

In order to be able to obtain uniaxial compressive stress-strain curves at strain rates close to the limit of Hopkinson bar techniques, Gorham developed in this laboratory a miniaturised version of the direct impact Hopkinson pressure bar $[89,105]$. The pressure bar is $3 \mathrm{~mm}$ in diameter and is intrumented with miniature $(0.64 \times 0.15 \mathrm{~mm})$ semi-conductor strain gauges. It can routinely test pinhead size specimens $1 \mathrm{~mm}$ in diameter and $0.5 \mathrm{~mm}$ thick at strain rates between $10^{4}$ and $10^{5} \mathrm{~s}^{-1}$. Since there is no input bar whose gauge record would normally give the strain rate and hence the strain, high-speed photography was 
initially used to record the diametral expansion and hence determine the strain. However, it was soon realised that this was not routinely necessary [178] (see figure 5), though useful as a check [89]. If for any reason, such as shear banding, the specimen does not remain cylindrical during the test, high-speed photography of the expansion of one plane section will not give an accurate measure of the strain from the time that this happens.

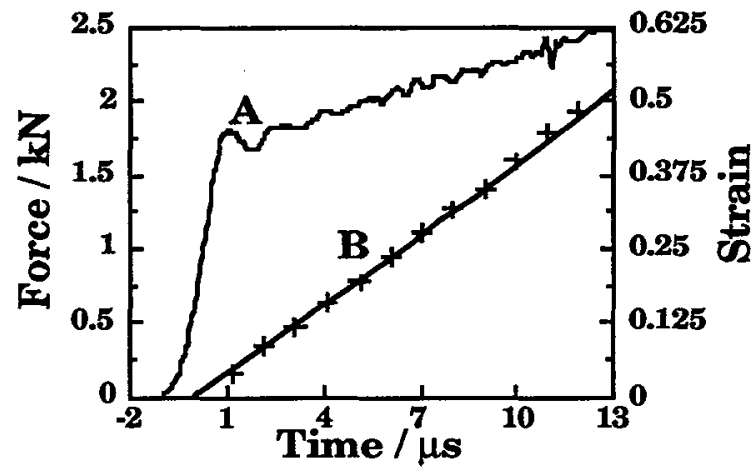

Figure 5. Plot showing the close agreement between strain measured using high-speed photography (indicated by + signs) and that calculated (line B) from the force pulse (line A) recorded from the output bar for a work-hardened W-Ni-Fe alloy (from refs. $[89,178]$ )

Two further advantages of miniaturisation are (i) that the range of frequencies which can be propagated without dispersion is increased (because a bar only becomes strongly dispersive at wavelengths commensurate with its diameter [89]) and (ii) the bar can be made from a hard, relatively brittle material like tungsten carbide allowing very strong materials such as tungsten to be tested (our $3 \mathrm{~mm}$ diameter WC bar has not yet broken, though it has been used many hundreds of times, whereas our conventional SHPB made from $12.5 \mathrm{~mm}$ diameter WC rods breaks after fewer than 100 tests). If it can be used, WC has another advantage in that its Poisson's ratio is smaller than that of many metals $(0.22$ as opposed to $\mathrm{ca}$. 0.3 for steels, 0.32 for titanium and 0.28 for tungsten [179]) which means that the frequency at which dispersion effects become important is higher for a bar made of WC than for one made from such metals [63] i.e. it can transmit stress-wave pulses with less distortion.

One common drawback of conventional SHPB systems is that specimens are loaded repeatedly by stress-wave reflections within the bars making microstructural investigations relatively pointless. However, a recent innovation by Nemat-Nasser and colleagues allows 'soft recovery' of specimens that have been loaded once and once only [180]. This can be achieved in compression, tension and torsion.

A summary of major developments in SHPB testing is given in Table 2.

Date

1949

1957

1960

1971

1973

1980

1980

1991
Major developments

Kolsky develops the SHPB

First report of dynamic biaxial testing

Harding develops the tensile SHPB

Duffy and co-workers develop the torsion SHPB

TABLE 2

Progress in SHPB testing

Biaxial (torsion-compression) SHPB

Gorham develops the miniaturised direct impact Hopkinson bar

First (published) use of microcomputer with SHPB

Nemat-Nasser develops one pulse loading SHPBs (compression, tension, and torsion) and soft-recovery techniques

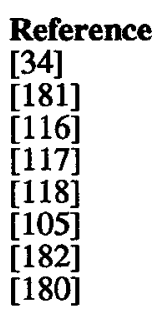




\section{THE UK PLATE IMPACT FACILITY}

\subsection{Shock Physics}

The study of states of matter at extreme static pressures was begun in the previous century and developed by Bridgman [183] into a well developed discipline. By the Second World War high explosives were commonly used to launch planar shock waves into materials, principally metals [184]. Over the intervening years the field has expanded to include high-speed guns in order to introduce shocks of precisely controlled amplitude and duration. Such tools have allowed experimentalists to access new thermodynamic states for extremely short time durations both complementing static high pressure work and defining new goals in the development of equations of state. The range of materials studied has concomitantly expanded from metals and explosives to the entire range of ductile and brittle materials, including composites, and from the measurement of material parameters to the synthesis of novel materials [185]. The new reader is directed to the several excellent review articles in the field which can be found listed in Davison and Graham [186]. Amongst the many possible areas of shock physics research, several have attracted recent attention and are presently under study in Cambridge. We describe some of this work below. At present our interests cover ceramics, metals, composites and glasses. Additionally we are developing a real time spectroscopy capability to study fundamental processes in the shock chemistry of condensed phase energetic materials. We are combining this with ultra-fast pyrometry in order to measure shock temperature.

In ballistic impact the triaxial strain state set up in the material lies somewhere between uniaxial strain and uniaxial stress. Uniaxial stress tests have been described above. The uniaxial strain configuration is also readily attained experimentally and easily analysed and is generally termed the plate impact experiment. A planar shock wave is induced in the specimen by impact from a flyer plate attached to the front of a sabot. Plate velocity and thus shock amplitude is accurately controlled and the induced stress wave profile is measured at some distance into the sample by one of several techniques. The centre of the sample material is uniaxially strained in the direction of the shock since this point is inertially confined until rarefaction waves can penetrate from the periphery of the sample and relieve the material by strains in the plane of the shock.

The stress-time histories provide benchmark tests for constitutive relations introduced into hydrocodes. However, although the plate impact data can test a model, the challenge to the theoretician is to devise a scheme by which the measured stress-time histories at several points within the sample can be used to deduce the entire deformation history and thus the appropriate constitutive relation. Such an endeavour has met with limited success in the past due to problems of non-steadiness in the waves [187189].

\subsection{Experimental Techniques}

The results presented below were collected from instrumented plate-impact experiments carried out on the single-stage gas gun at the Cavendish laboratory $\left(50 \mathrm{~mm}\right.$ bore, $1 \mathrm{~km} \mathrm{~s}^{-1}$ maximum impact velocity). We have the capability to do a range of measurements in impact studies summarised in Table 3. Uniaxial strain compressive shock and release waves are recorded after travel through target tiles backed with PMMA blocks. The longitudinal stress normal to the planar wave fronts is recorded using piezoresistive stress gauges embedded $1 \mathrm{~mm}$ away from the sample/PMMA interface in the backing block.

\section{TABLE 3}

\section{Experimental techniques available}

Variable Measured

Longitudinal and transverse stress

Surface strain measurements

Spall strength and dynamic compressive strength measurements (HEL)

Soft recovery experiments on brittle materials Waves structure in transparent materials 3D long rod penetration

Taylor test

\section{Experimental Technique} Manganin, PVDF transducer sampled to $1 \mathrm{GS} \mathrm{s}^{-1}$ Strain gauges, in-plane displacement and projection moire with high-speed photography Manganin transducer sampled to $1 \mathrm{GS} \mathrm{s}^{-1}$

Star shaped flyer, momentum traps etc. High-speed photography / gauges

High-speed photography / gauges / reverse ballistic

High-speed photography / soft recovery 
The PMMA backing is chosen because it acoustically matches both the gauge's backing material and the epoxy used to assemble the sample. The signal recorded thus follows the form of the stress history accurately and with minimal smoothing of discontinuous stress rises (signal rise times of $\mathrm{ca} .30 \mathrm{~ns}$ are typical on elastic waves). In other experiments the gauge is embedded between two blocks of the target. In this configuration, however, the rise time of the wave is limited to $c a .80 \mathrm{~ns}$.

The gauges used at Cambridge are MicroMeasurements manganin gauges and the calibration data of Rosenberg et al. [190] are used in reducing the voltage data collected. The signals are recorded using a fast $\left(1 \mathrm{GS} \mathrm{s}^{-1}\right)$ digital storage oscilloscope and transferred onto a micro-computer for data reduction. Impact velocity is measured to an accuracy of $0.5 \%$ using a sequential pin-shorting method and tilt is adjusted to be less than $1 \mathrm{mrad}$ by means of an adjustable specimen mount. Impactor plates are made from lapped copper and aluminium discs and are mounted onto a polycarbonate sabot with a relieved front surface in order that the rear of the flyer plate remains unconfined. The gauge is included as one arm of a pulsed Wheatstone bridge circuit. In the case of very fast rising signals (for instance the elastic wave in ceramics) the output signal can rise in 20-30 ns. This approaches the theoretical limit attainable with foil gauges since the stress within the gauge must be allowed to equilibrate to the external stress by ringing up of the induced compression wave within the foil (usually taken to be three wave transits of the gauge). The very rapid mismatching of the circuitry can give rise to spurious electrical ringing which by careful electronic design we have been able to remove. We have an ongoing program of power supply improvements in progress.

The role of shear strength in controlling the ballistic performance of a shock loaded solid has recently been emphasised. The only technique capable of a direct measurement of this quantity is to measure simultaneously both longitudinal and lateral stress using thin piezoresistive gauges. The analysis of the data obtained is simple since the shear stress is equal to half the difference between the longitudinal and lateral stresses. In order to account for the response of the lateral gauge a careful analysis of its loading and unloading characteristics was needed. Such studies have resulted in some debate which has now been resolved allowing the technique to be applied generally (see the summary and references in Rosenberg \& Brar [191]). We have applied the technique in several areas but we use as illustration the compression behaviour of float glass (see below).

Whilst we favour manganin stress gauges for our work there are several other available candidates. Any gauge needs to be able to satisfy the following requirements:

(i) High sensitivity to pressure,

(ii) low sensitivity to temperature,

(iii) stable resistance with time,

(iv) low sensitivity to composition and manufacturing techniques,

(v) linear (or very nearly so) response to pressure,

(vi) no phase transitions in working pressure range.

Manganin fits all of these requirements but ytterbium and carbon are also used in low stress regimes and in some explosive work even though several of the requirements are violated. Piezoelectric gauges have been used for many years and a wealth of literature exists on their polarisation under shock. The most notable of these materials are quartz, PZT and lithium niobate (see Graham \& Reed [192] and the references therein). Recently interest has centred around poly-vinylidene difluoride (PVDF); a piezoelectric polymer [193]. Such piezofilms are of interest as potential gauge materials since they have high output and offer the opportunity of dispensing with power supplies. At present the response of these gauges is limited by the thickness of the film to $c a .100 \mathrm{~ns}$. These gauges can be used in one of two different configurations denoted charge mode and current mode. In the former the gauge sees a charge integrator and the output can be sent directly to an oscilloscope to measure a voltage proportional to the stress. In the latter, a current viewing resistor is placed across the gauge and the voltage across it is monitored directly. In this case the stress derivative is measured and a time integration must be carried out to recover the stress signal. It is this latter method which is generally favoured because of the bandwidth problems of hardware integrators. We have manufactured our own gauges and have simultaneously measured wave profiles in ceramics with both manganin and PVDF gauges with good results [194]. In figure 6 we show typical gauge records taken with manganin (solid line) and PVDF (dotted line). The gauges were placed next to one another in PMMA. The target was a ceramic with a very rapidly rising elastic pulse impacted so as to achieve a stress of $c a .0 .5$ of the dynamic compressive strength (Hugoniot Elastic limit; HEL). Note the relatively longer rise time for the PVDF and the discrepancy in the PVDF reloading signal which needs further investigation. 


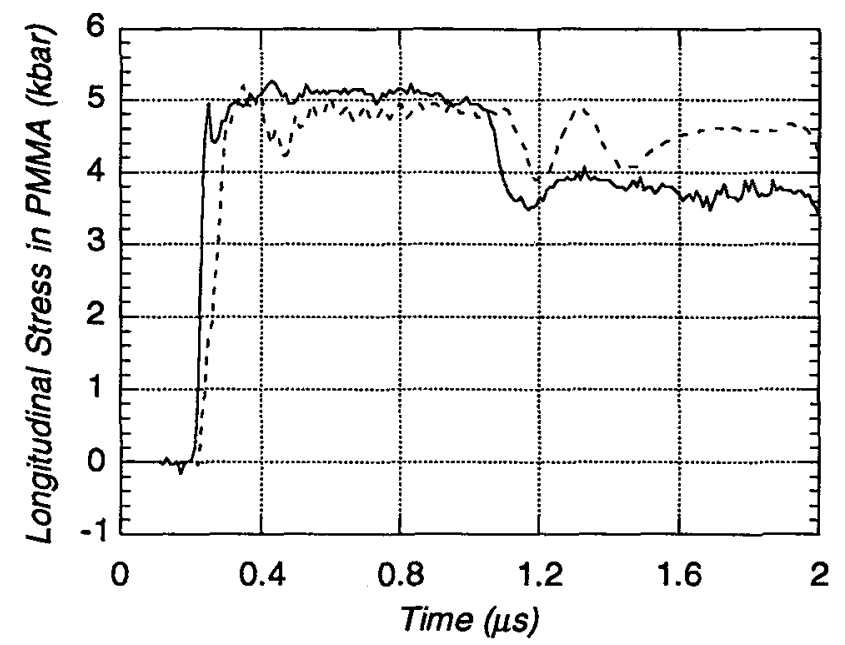

Figure 6. A comparison of manganin (solid line) and PVDF (dotted line) gauges. 3 mm aluminium flyer impacting at $270 \mathrm{~m} \mathrm{~s}^{-1}$ on a ceramic with very fast rising compression pulse.

Many laboratories (particularly Sandia National Laboratory) have chosen to develop velocity interferometry to measure the free (usually rear) surface velocity of the target. This velocity can be related via the shock impedance to the induced stress and the stress-time history can thus be inferred. The most versatile instrument of this type is the VISAR (Velocity Interferometer System for Any Reflector) [195] which dispenses with the need to have a reflective rear surface thus allowing measurements to be taken on deforming surfaces. Clifton has used normal and transverse velocity interferometry to determine the stressstrain curves for materials at high shear strain rates in the so called pressure-shear configuration [196, 197].

Finally we briefly note the use of high-speed streak photography in the measurement of shock wave velocities. In early work this technique was very important. Recently with the advent of gauges, recording techniques and the push to gain stress-time histories, the technique has reduced in importance except in the recording of spectroscopic work. However, high-speed streak and framing photography still has an important place in understanding the processes occurring within a shocked solid. In designing our facility several large optical ports were constructed through which we have photographed shock deformation in a variety of materials. We report one of these studies on failure waves in glass in these proceedings [198]. As an illustration of some of our work and the value of gauge studies we now discuss some grain size effects in ceramics and some gauge experiments conducted on float glass.

\subsection{Ceramics}

Work first started on high strength ceramics in the US in the early 1970 s $[199,200]$. Over the last ten years there has been renewed interest in studies of the compressive and tensile strength properties of these ceramics (principally aluminas) in order to understand how they might be incorporated into armour systems or turbine blades [201,202]. Of interest is the physical meaning of the quantity known as the Hugoniot elastic limit (HEL) in a ceramic. There is considerable evidence from recovery experiments $[203,204]$ showing that aluminas with a glassy phase show considerable cracking below the HEL [197]. Longy et al. [205] have claimed that in the case of high density aluminas with no glass phase and low porosity, samples can be recovered after loading to several times the HEL with limited cracking but showing some plastic deformation. For a selection of aluminas with a glassy phase we have not found any evidence of spall strength remaining in the ceramic after impact to or above the HEL value [206, 207]. It thus seems probable that the HEL corresponds in this case to a crack coalescence criterion. We have also shown features of wave propagation in aluminas that show variation with grain size; for instance that the elastic precursor in aluminas decays with distance and that this property correlates with a Hall-Petch dependence[207, 208]

As an example of some of these effects, four typical experiments are shown for aluminas with similar physical properties. These aluminas have properties summarised in Table 4 (further details can be found in Bourne et al. [207]). The materials were constructed so as to produce as closely similar materials as 
possible but by using a higher firing temperature it was hoped that Deranox 4 would have a larger grain size. In fact the two materials differ also in alumina content and glass content.

\section{TABLE 4}

Alumina properties

$\begin{array}{lll}\text { Property } & \text { Deranox 3 } & \text { Deranox 4 } \\ \mathrm{Al}_{2} \mathrm{O}_{3}(\%) & 97.4 & 96.3 \\ \text { Glass content }(\%) & 2.6 & 3.7 \\ \text { Density }\left(\mathrm{g} \mathrm{cm}^{-3}\right) & 3.93 & 3.91 \\ \text { Porosity }(\%) & 3.6 & 3.8 \\ \text { Mean Grain Size }(\mu \mathrm{m}) & 4 & 8 \\ \text { Longitudinal sound speed / } \mathrm{km} \mathrm{s}^{-1} & 10.27 & 10.15\end{array}$

Stress levels are shown in the PMMA backing in which the gauge is sitting. In figure $7 a$, spall experiments are shown in which the stress level is around half the HEL. In this case the flyer plate is aluminium with a thickness of $3 \mathrm{~mm}$ and having a velocity of $c a .270 \mathrm{~m} \mathrm{~s}^{-1}$. In figure $7 b$, a $3 \mathrm{~mm}$ thick copper flyer plate fired at $c a .550 \mathrm{~m} \mathrm{~s}^{-1}$ induces stresses which exceed the HEL of the materials. In figure $7 a$ the initial rise of the wave is very fast as we might expect for elastic waves in a ceramic. The spall strength of the two materials can be judged from the relative heights of the second compression waves which arrive at the gauge location after $c a .1 \mu \mathrm{s}$. It is clear from the traces that the spall strength for Deranox 4 is reduced in comparison with that of Deranox 3 and that Deranox 4 shows a more rounded form to the pull back signal indicating perhaps a more uneven spall plane. The HEL of a ceramic can be measured from the position of the break in slope of the rising part of the gauge record. Thus the HEL of Deranox 4 is nearly half that of Deranox 3 which is to be expected given its larger grain size.

After release, the gauge records show no second compression showing that above the HEL there is no spall strength left in the material. This suggests that the HEL corresponds to a criterion for crack interconnection at least in this class of glassy ceramics. It can also be seen that the stress wave rises more slowly to the Hugoniot stress in Deranox 4. This indicates that the shock travels more slowly in Deranox 4, which is indicative of greater energy dissipation from the original shock. Analytical modelling of such behaviour has been attempted using an approach incorporating crack nucleation and extension [209, 210]. Elastoplastic models have been used with limited success in hydrocodes to describe the material response, the most commonly used at present being the Johnson-Holmquist model [211]. It seems that in the long term a model based on the Griffith failure criterion to replace the presently used von Mises (or Tresca) is the only formulation that will ultimately model all the features of brittle response. Such an approach has been used by Rosenberg to explain the relation between HEL and spall strength and in the prediction of the shear strength of a range of ceramics with some success $[212,213]$.

a).

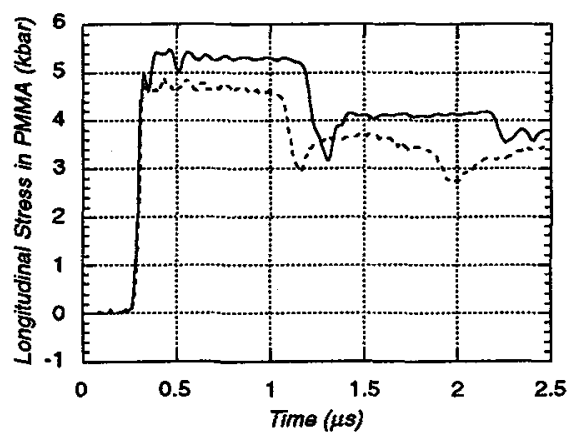

b).

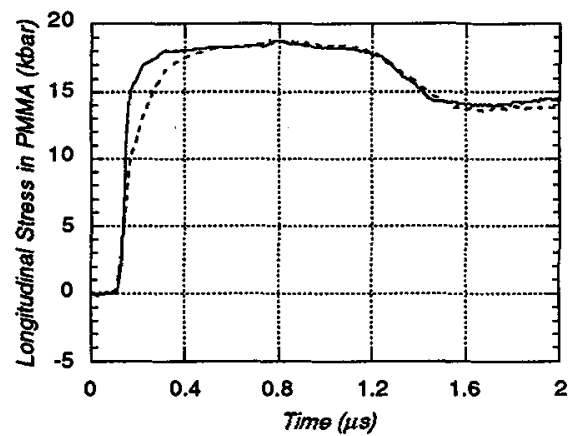

Figure 7. Impacts on deranox aluminas. The large grain size alumina (dotted line) is compared with a material of around half the grain size (solid line). In a). spall signals are shown induced by impact of 3 mm aluminium flyer plate travelling at ca. $270 \mathrm{~m} \mathrm{~s}^{-1}$. In b). impact stresses are above the HELs induced by impact by $3 \mathrm{~mm}$ Cu flyer plates at ca. $550 \mathrm{~m} \mathrm{~s}^{-1}$. 


\subsection{Glasses}

In contrast to work on ceramics where the HEL is associated with a reduction of the spall strength to zero, the interpretation of the significance of the HEL in glasses is clearly different. Brar et al. have shown that the spall strength of the material behind the shock front remains finite even when shocked to above the HEL [214]. However, they found that a failure wave ran behind the shock and that behind this the spall strength fell to zero as observed earlier by Kanel and his co-workers [215]. In order to investigate this phenomenon and to clarify the meaning of the failure wave we conducted a series of plate impact tests with simultaneous high-speed photography to observe the waves (the results of which appear elsewhere in these proceedings [198]). The gauge experiments have utilised the lateral gauge technique described above. In each of the two experiments for which traces are shown in figure 8 the impactor was a $6 \mathrm{~mm}$ thick copper plate. The sample was float glass of density $2490 \mathrm{~kg} \mathrm{~m}^{-3}$ and longitudinal sound speed 5.92

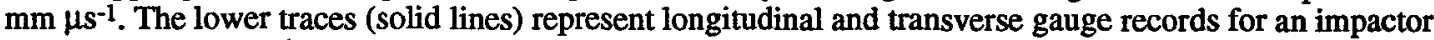
velocity of $610 \mathrm{~m} \mathrm{~s}^{-1}$. The longitudinal record for an impact at $750 \mathrm{~m} \mathrm{~s}^{-1}$ is also presented (dotted line). The longitudinal gauges were placed on the rear surface of the glass block in PMMA as described above and the shock reflects from the PMMA/glass interface back into the shocked material as a release. The rise shows a ramping, viscous response. There is a break in slope at $\mathbf{4 0} \mathrm{kbar}$ but it is probable that this is not the material's HEL. After the initial rise, the stress in both the lateral and longitudinal traces drop slightly. Simultaneous high-speed photography associates this dip with a dark front visible in the pictures. The ratio of the longitudinal to lateral stress is initially $c a .3: 1$ as expected from elasticity theory with a Poisson's ratio of 0.25 .

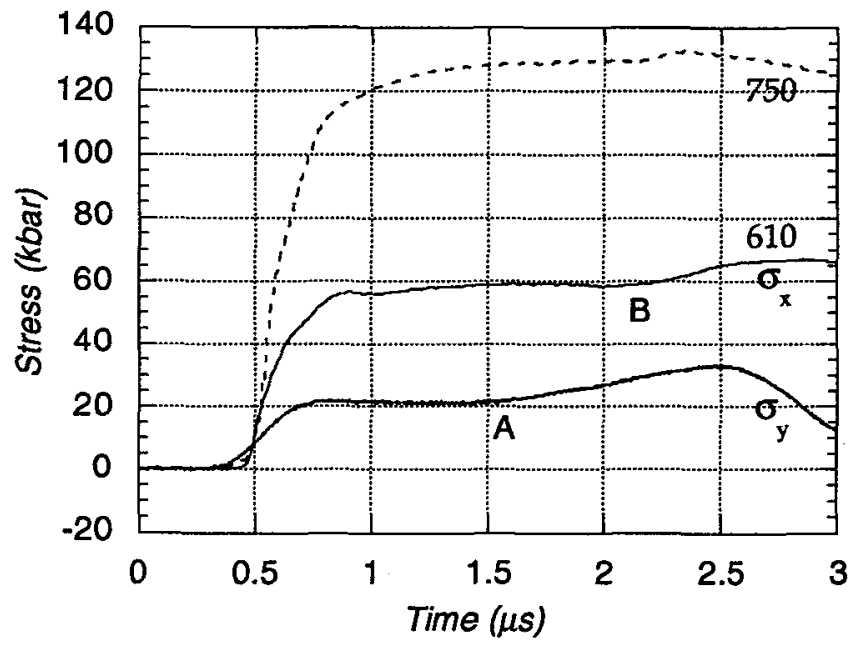

Figure 8. Plate impact experiments on float glass at 610 (solid line) and $750 \mathrm{~m} \mathrm{~s}^{-1}$ (dotted line). The impactor is in each case a $6 \mathrm{~mm}$ thick copper plate. The lower traces represent the longitudinal and transverse gauge measurements for the same experiment. The wave $A$ is the arrival of the failure wave at the transverse gauge. The wave $B$ represents the arrival of a compressive reflection from the failure wave at the gauge location. The same feature can be seen on the higher velocity shot.

The feature A represents the arrival of a failure wave at the lateral location. The convergence of the lateral and longitudinal records from $\mathrm{A}$ onwards indicates the reduction in the shear strength across the failure wave. That this is gradual is a result of the fact that the wave is sweeping the thickness of the lateral gauge. It will be seen that the value of the lateral stress never reaches that of the longitudinal stress since the release from the rear of the flyer arrives before complete loss of strength. The calculated value for the failure wave velocity deduced from similar records suggests strongly to us that the wave decelerates rapidly as it moves through the material. The rise in lateral stress at $\mathrm{A}$ is not mirrored in a corresponding rise in longitudinal stress. However at point $B$ the longitudinal stress does rise. This is due to the arrival of a compression wave which is a reflection from the failure front of the release from the gauge location. The same feature can be seen on the qualitatively similar high velocity trace coming in at the same time. 
The behaviour of glass represents a good illustration of the value of measuring wave profiles in order to deduce damage mechanisms. We hope to develop a theory to encompass such measurements into a complete constitutive description. Other glass types we have tested (borosilicate and various highly filled lead glasses) show very different behaviours from that described here. It is clear that this area needs much further investigation.

\section{OPTICAL TECHNIQUES FOR DYNAMIC STRESS ANALYSIS}

Many optical techniques have been developed for the measurement of displacement, strain and stress. Conventional strain gauges can provide measurements at a single point, and combine a high degree of accuracy (a few microstrain) with good time resolution (potentially of the order of ns, given a suitable amplifier). However, strain gauges have two significant disadvantages: (i) they only give information at one point in the field of view and (ii) bonding the gauge to the specimen may provide local reinforcement which perturbs the stress field. Optical techniques, on the other hand, generally provide wholefield information and many are also non-contacting.

Many of the optical techniques currently used for studying dynamic events were originally developed for quasi-static applications. The Handbook on Experimental Mechanics [216] provides an excellent background to the use of optical methods in experimental mechanics. In this section we outline the most frequently-used techniques, typical applications, and some promising new methods. Table 5 provides a concise summary.

TABLE 5

\begin{tabular}{|c|c|c|c|c|c|}
\hline \multirow[b]{2}{*}{ Method } & \multicolumn{5}{|c|}{ Summary of optical techniques for dynamic stress analysis } \\
\hline & Measurand & Sensitivity & Accuracy & Light & Reference \\
\hline Photoelasticity & $\sigma_{1}-\sigma_{2}$ & Variable & Variable & Incoherent & [216-218] \\
\hline Caustics & $\partial u_{7} / \partial x, \partial u_{z} / \partial y$ & Variable & Variable & Incoherent & {$[216,219]$} \\
\hline $\begin{array}{l}\text { Moiré } \\
\text { interferometry }\end{array}$ & $u_{\mathrm{x}}$ or $u_{\mathrm{y}}$ & $\begin{array}{l}\text { Grating pitch } \\
p \approx \lambda\end{array}$ & $\sim p / 10$ & Coherent & $\begin{array}{l}{[216,220,} \\
221]\end{array}$ \\
\hline $\begin{array}{l}\text { Moiré } \\
\text { photography }\end{array}$ & $u_{\mathrm{x}}$ or $u_{\mathrm{y}}$ & $\begin{array}{l}\text { Grating pitch } \\
p \approx 5-1000 \mu \mathrm{m}\end{array}$ & $\sim p / 10$ & Incoherent & {$[216,222]$} \\
\hline $\begin{array}{l}\text { Speckle } \\
\text { photography }\end{array}$ & $u_{\mathrm{x}}$ and $u_{\mathrm{y}}$ & $\begin{array}{l}\text { Speckle } \\
\text { diameter } \\
\sigma \approx 5-50\end{array}$ & $\begin{array}{l}\sim 0.2 \sigma^{2} / \text { (spatial } \\
\text { resolution) }\end{array}$ & Coherent & $\begin{array}{l}{[216,223,} \\
224]\end{array}$ \\
\hline $\begin{array}{l}\text { Speckle } \\
\text { interferometry }\end{array}$ & $u_{\mathrm{x}}, u_{\mathrm{y}}$ or $u_{\mathrm{z}}$ & $-\lambda$ & $-\lambda / 10$ & Coherent & {$[216,225]$} \\
\hline $\begin{array}{l}\text { Holographic } \\
\text { interferometry }\end{array}$ & $u_{\mathrm{x}}, u_{\mathrm{y}}$ and $u_{\mathrm{z}}$ & $\lambda / 2$ & $\sim \lambda / 50$ & Coherent & {$[216,226]$} \\
\hline $\begin{array}{l}\text { Shearing } \\
\text { interferometry }\end{array}$ & $\partial u_{z} / \partial x$ or $\partial u_{z} / \partial y$ & $\begin{array}{l}\sim \lambda /(\text { shear } \\
\text { distance) }\end{array}$ & $\begin{array}{l}\sim 0.1 \lambda /(\text { shear } \\
\text { distance) }\end{array}$ & Coherent & [227] \\
\hline
\end{tabular}

\subsection{Photoelasticity}

This is one of the oldest and widely-used photomechanics methods, and relies on the fact that transparent materials become birefringent under an applied load. The birefringence is made visible by placing the sample between circular polarisers. A so-called isochromatic fringe pattern is formed, which in 2-D represents contours of $\sigma_{1}-\sigma_{2}$ where $\sigma_{1}$ and $\sigma_{2}$ are the principal in-plane stresses. The fringe sensitivity varies by several orders of magnitude between materials (e.g. $-400 \mathrm{kN} \mathrm{m}^{-1}$ fringe-1 for glass to $0.2 \mathrm{kN} \mathrm{m}^{-1}$ fringe $^{-1}$ for polyurethane rubber). Cranz-Schardin cameras are often used to record the fringe patterns due to their good spatial resolution. Photoelasticity is an appropriate technique for studying the response of model structures but is less useful for investigating the mechanical properties of opaque materials. It has been used extensively in dynamic fracture studies [217] where the dynamic stress intensity factor, $\mathrm{K}_{\mathrm{Id}}$, can be estimated by least-squares fitting a series expansion of the theoretical stress field to the measured fringe pattern. Another example is visualisation of stress wave propagation through model granular materials [218]. There are, however, many other applications in the literature.

\subsection{The method of caustics}

This approach was proposed by Manogg [219] and used extensively by Theocaris [220], Kalthoff [221], Rosakis [222] and others, mainly for studies of dynamic fracture. A collimated beam of light illuminates the specimen surface and the reflected or transmitted beam is recorded by a camera focused on a plane separated from the specimen surface by a small distance. The intensity distribution depends on the surface slope distribution (and hence on the in-plane stresses), but the analysis of general stress fields is difficult. In the presence of a crack, however, the surface displacement of the specimen is inversely 
proportional to the square root of distance from the crack tip and the caustic pattern forms a characteristic, approximately circular, dark region centred on the crack tip. The diameter of this 'shadow spot' can be related directly to $K_{\text {Id }}$. One of the main advantages of the technique is its experimental simplicity. If the crack is moving, it is even possible to multiply-expose a single picture using a strobed light source, thereby avoiding the need for a high speed camera.

\subsection{Moiré techniques}

A family of moire techniques can be used to measure in-plane and out-of-plane displacement fields. For in-plane displacements, a grating is attached to the specimen surface. The grating can be recorded directly onto film, but the usual approach when the strains are low is to form moire fringes by superimposing a second reference grating of almost the same spatial frequency. The camera need then only resolve the fringe pattern and not the grating lines. The pattern represents a contour map of the in-plane displacement component perpendicular to the grating lines, with a contour interval or 'sensitivity' equal to the pitch $p$ of the specimen grating. Specimen grating frequencies of up to about 40 lines per mm (sensitivity $=25 \mu \mathrm{m}$ ) can be used with white light illumination, but the sensitivity is dramatically improved (to sub-micron values) by the use of coherent light. The technique is then known as moiré interferometry. Applications include visualisation of stress waves in graphite epoxy composites [223] and dynamic fracture studies [224]. Intermediate sensitivities $(5-10 \mu \mathrm{m})$ can be achieved by high resolution moiré photography [225], first proposed by Burch and Forno, in which the specimen grating is imaged onto the reference grating with a masked camera lens. Figure 9 shows a high speed sequence of moiré fringe patterns produced in a polymethyl methacrylate (PMMA) plate following impact by a steel ball. The combination of an accuracy of $\sim 1 \mu \mathrm{m}$ together with microsecond time resolution make this method attractive for the dynamic stress analysis of many polymers and composites.

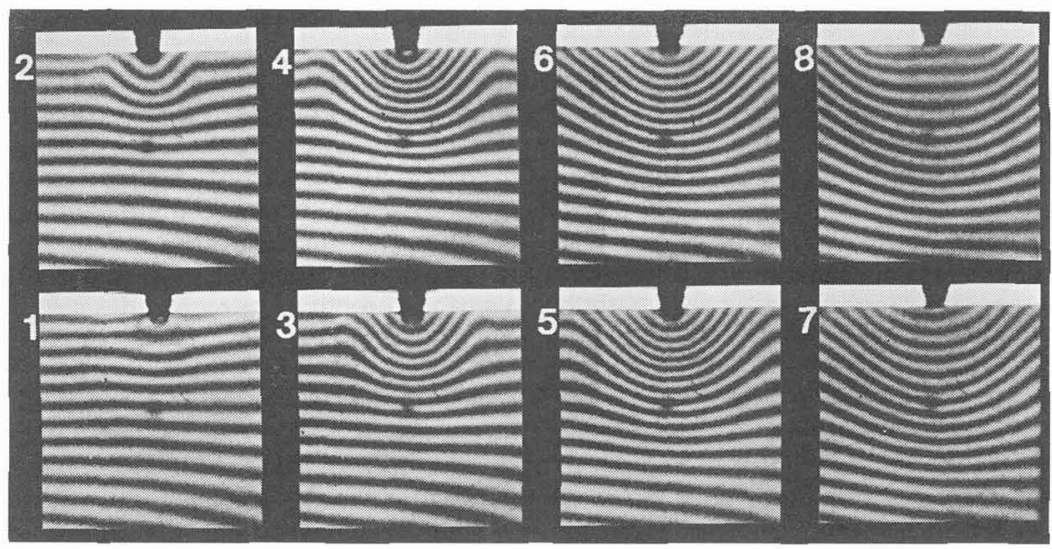

Figure 9. High resolution moiré fringe patterns showing displacement field produced by steel ball impact on PMMA. Horizontal grating, pitch $=6.7 \mu \mathrm{m}$, interframe time $=0.95 \mu \mathrm{s}$, field of view $=16 \times 16 \mathrm{~mm}^{2}$.

\subsection{Laser speckle}

A range of techniques is based on the phenomenon of laser speckle, which is the granular pattern produced when a rough surface is illuminated by coherent light. The simplest method (laser speckle photography) involves recording double exposure photographs of the object. The speckle pattern moves as though it were physically present on the specimen surface, so the displacement field occurring between the two exposures can be mapped out by measuring the speckle displacement point by point from the developed photograph. This is normally done by probing the photograph with a narrow laser beam and measuring the spacing and angle of the Young's fringes in the diffraction halo. Figure 10 shows a double exposure photograph of a fast crack in PMMA recorded by a double-pulsed ruby laser with open-shutter camera. The Young's fringes produced by probing the photograph at several points are also shown. Figure 11 is the displacement field deduced by measuring 256 such fringe patterns. 


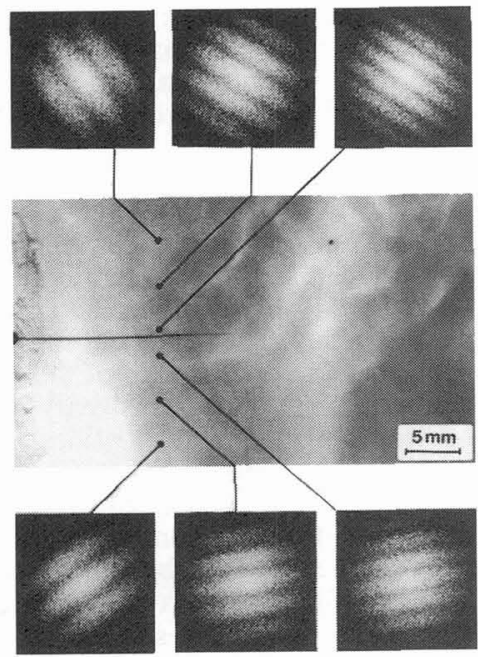

Figure 10. Double exposure speckle photograph of fast crack in PMMA. Time between exposures $=15$ $\mu$; crack velocity $\approx 300 \mathrm{~m} \mathrm{~s}^{-1}$.

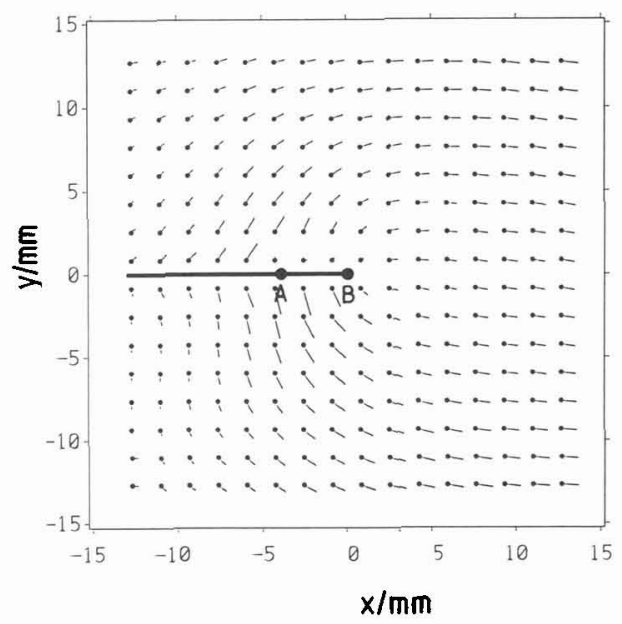

Figure 11. Displacement field measured from Young's fringe patterns, produced by pointwise filtering the photograph in Fig. 10.

The random error in the measured displacement component scales as the square of the diameter $\sigma$ of the smallest speckle that can be resolved by the imaging system [226]. High speed cameras with good spatial resolution are therefore necessary when recording sequences of speckle photographs. CranzSchardin cameras are unsuitable because light is scattered into all the lenses on each light pulse. Rotating mirror cameras with pulsed ruby laser light sources can, however, measure displacement fields to submicron accuracy with fields of view of several tens of $\mathrm{mm}$ and a time resolution of order $1 \mu \mathrm{s}$ [227]. The advantage of speckle photography over other techniques is that it is literally non-contacting and can be used on specimens with rough surfaces with little or no surface preparation required.

\subsection{Speckle interferometry}

This technique relies on the interference between two speckle patterns or a speckle pattern and smooth reference wave. Depending on the optical configuration, it can be used to measure in-plane or outof-plane displacement fields. Double exposure photographs are recorded, and changes in speckle correlation due to the object displacement are made visible by spatial filtering. Figure 12 is a sequence of fringe patterns from an in-plane speckle interferometer used to measure the transient displacement field round a stationary crack in an aluminium plate. The crack was loaded with a compressive stress pulse, and the exposures were recorded with a single pulse ruby laser [228]. The sequence was built up by repeating the experiment several times with different time delays between the impact and laser pulse, but could have been recorded as one sequence using the camera/laser system described in Huntley \& Field [227]. The fringe pattern represents the same quantity (horizontal displacement component) with the same sensitivity $(0.4 \mu \mathrm{m})$ as would be obtained with moiré interferometry, but no grating was required on the specimen surface. 


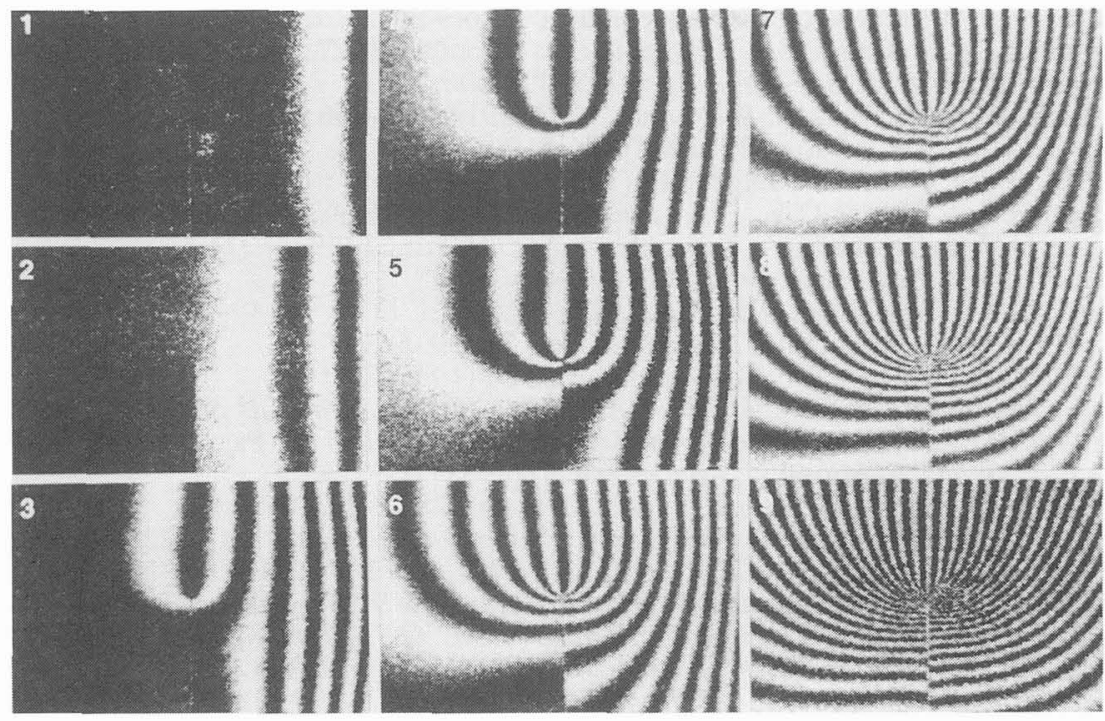

Figure 12. Speckle interferometry fringe patterns showing the interaction of a stress wave with a vertical crack.

\subsection{Holographic interferometry}

This is a related technique in which a double exposure hologram is recorded of the object before and after deformation, using a double-pulsed ruby laser for example. When the hologram is reconstructed, a fringe pattern is observed which can be related to the displacement component along the bisector of the illumination and viewing directions. The technique produces very high quality fringe patterns, requires no specimen preparation, and can be used whenever a 'snapshot' of the displacement field is required. Fällström et al. [229] describe one example of its application to the visualisation of waves in isotropic and anisotropic plates. It is difficult, however, to record sequences of holograms with a high speed camera.

\subsection{Shearing interferometry}

This has recently been applied to dynamic fracture experiments under the name 'coherent gradient sensor' [230]. An interference pattern is formed between two copies of the image, one of which has been laterally shifted or 'sheared' relative to the other. The fringes represent contours of constant surface gradient. The surface must have a mirror finish, but this has the advantage that the technique is much more efficient in its use of the available light than speckle or holographic methods, so that much lower power lasers (e.g. cavity-dumped argon ion, rather than Q-switched ruby) can be used.

\section{ACKNOWLEDGEMENTS}

The Cambridge research in this area has been sponsored by SERC, MOD and the Royal Society. In particular, we thank Drs W.A. Carson, I.G. Cullis, I.G. Crouch, B. Goldthorpe, Z. Rosenberg and Y. Mebar for their encouragement and advice in setting up the 1-D plate impact facility.

\section{REFERENCES}

1. Thomas Young "A Course of Lectures on Natural Philosophy and the Mechanical Arts: Vol. 1", pp. 144-148, publ. Joseph Johnson, London, 1807.

2. Hopkinson J., Proc. Manchest. Liter. Philos. Soc. 11 (1872) 40-45.

3. Hopkinson J., Proc. Manchest. Liter. Philos. Soc. 11 (1872) 119-121.

4. "Symposium on Impact Testing of Materials", Proc. Amer. Soc. Testing Materials 22 (part 2) (1922) 5-248 (has a bibliography going back to 1825)

5. $\quad$ Clark D.S., Trans. Amer. Soc. Metals 46 (1954) 34-62.

6. $\quad$ Pochhammer L., J. reine angew. Math. 81 (1876) 324-336.

7. Barré de St. Venant "Theorie de l'Élasticité des Corps Solides de Clebsch". pp. 480a-d (final note to para 60), publ. Dunod, Paris, 1883.

8. $\quad$ Chree C., Trans. Camb. Philos. Soc. 14 (1889) 250-369. 
9. Love A.E.H., "A Treatise on the Mathematical Theory of Elasticity: 4th Edn.",pp. 1-31 (Historical Introduction), publ. Cambridge University Press, London, 1927. Republ. Dover, New York, 1944.

10. Hopkinson B., Proc. R. Soc. Lond. 74 (1905) 498-506.

11. Hopkinson B., Phil. Trans. R. Soc. Lond. A213 (1914) 437-456.

12. Taylor G.I., J. Inst. Civil Eng. 26 (1946) 486-519.

13. Guest J.J., Proc. Inst. Mech. Engrs 119 (1930) 1273-1304.

14. Luerssen G.V. \& Greene O.V., Proc. Amer. Soc. Testing Materials 33 (1933) 315.

15. Luerssen G.V. \& Greene O.V., Trans. Amer. Soc. Metals 22 (1934) 311.

16. Mason W., Proc. Inst. Mech. Engrs 128 (1934) 409-438.

17. Luerssen G.V., Trans. Amer. Soc. Metals 23 (1935) 861.

18. Mann H.C., Proc. Amer. Soc. Testing Materials 35 (1935) 323-340.

19. Mann H.C., Proc. Amer. Soc. Testing Materials 36 (1936) 85-109.

20. "Symposium on Impact Testing", Proc. Amer. Soc. Testing Materials 38 (Part 2) (1938) 21-156.

21. Clark D.S. \& Dätwyler G., Proc. Amer. Soc. Testing Materials 38 (Part 2) (1938) 98-111.

22. Davis E.A., Trans. ASME 60 (J. Appl. Mech. 5) (1938) A137-A140

23. Greene O.V. \& Stout R.D., Trans. Amer. Soc. Metals 28 (1940) 277-305.

24. Manjoine M. \& Nadai A., Proc. Amer. Soc. Testing Materials 40 (1940) 822-839.

25. Brown A.F.C. \& Vincent N.D.G., Proc. Inst. Mech. Engrs 145 (1941) 126-134.

26. Nadai A. \& Manjoine M.J., Trans. ASME 63 (J. Appl. Mech. 8) (1941) A77-A91.

27. Fehr O., Parker E.R. \& DeMichael D.J., Trans. ASME 66 (J. Appl. Mech. 11) (1944) A65-A71

28. Manjoine M.J., Trans. ASME 66 (J. Appl. Mech. 11) (1944) A211-A218.

29. MacGregor C.W. \& Fisher J.C., Trans. ASME 67 (J. Appl. Mech. 12) (1945) A217-A227.

30. Warnock F.V. \& Brennan J.B., Proc. Inst. Mech. Engrs 159 (1948) 1-10.

31. Warnock F.V. \& Taylor D.B.C., Proc. Inst. Mech. Engrs 161 (1949) 165-175.

32. Taylor G.I., Proc. R. Soc. Lond. A194 (1948) 289-299.

33. Whiffin A.C., Proc. R. Soc. Lond. A194 (1948) 300-322.

34. Kolsky H., Proc. Phys. Soc. Lond. B62 (1949) 676-700.

35. Duwez P.E. \& Clark D.S., Proc. Amer. Soc. Testing Materials 47 (1947) 502-532.

36. von Kármán T. \& Duwez P., J. Appl. Phys. 21 (1950) 987-994.

37. Perzyna P., Bull. Acad. Pol. Sci. (Sér. Sci. Tech.) 7 (1959) 201-203.

38. Plass H.J. Jr. \& Wang N.-M. In "Proc. 4th Midwestern Conference on Solid Mechanics", pp. 331348, publ. University of Texas, Austin, Texas, 1959.

39. Critescu N., Bull. Acad. Pol. Sci. (Sér. Sci. Tech.) 11 (1963) 129-133.

40. Bell J.F., "The Physics of Large Deformation of Crystalline Solids" (Springer Tracts in Natural Philosophy: Vol. 14), publ. Springer-Verlag, Berlin, 1968.

41. Wilkins M.L. \& Guinan M.W., J. Appl. Phys. 44 (1973) 1200-1206.

42. Hashmi M.S.J. \& Thompson P.J., Int. J. Mech. Sci. 19 (1977) 273-283.

43. Woodward R.L. \& Lambert J.P., Int. J. Mech. Sci. 23 (1981) 497-501.

44. Johnson G.R. \& Cook W.H. In "Proc. 7th Int. Symp. on Ballistics", The Hague, The Netherlands, pp. 541-547, publ. 1983.

45. Johnson G.R. \& Cook W.H., Engng Fract. Mech. 21 (1985) 31-48.

46. Zerilli F.J. \& Armstrong R.W., J. Appl. Phys. 61 (1987) 1816-1825.

47. Johnson G.R. \& Holmquist T.J., J. Appl. Phys. 64 (1988) 3901-3910.

48. Zerilli F.J. \& Armstrong R.W. In "Shock Waves in Condensed Matter - 1987", ed. S.C. Schmidt \& N.C. Holmes, p. 273, publ. Elsevier, Amsterdam, 1988.

49. Zerilli F.J. \& Armstrong R.W., J. Appl. Phys. 68 (1990) 1580-1591.

50. Holmquist T.J. \& Johnson G.R., J. Phys. IV France 1 (1991) Colloq. C3 (DYMAT 91) 853-860.

51. Partom Y. In "Proc. 13th Int. Symp. Ballistics: Vol. 3", ed. Á. Persson, K. Andersson \& E.B. Björck, pp. 291-298, publ. National Defence Research Establishment, Sundyberg, Sweden, 1992.

52.

53. Holt W.H., Mock W.Jr. , Zerilli F.J. \& Clark J.B., Mech. Mater. 17 (1994) 195-202.

Hutchings I.M., J. Mech. Phys. Solids 26 (1978) 289-301

54. Kukureka S.N. \& Hutchings I.M. In "Proc. 7th Int. Conf on High Energy Rate Fabrication", ed. T.Z. Blazynski, pp. 29-38, publ. University of Leeds, Leeds, 1981.

55. Hawkyard J.B., Eaton D. \& Johnson W., Int. J. Mech. Sci. 10 (1968) 929-948.

56. Gust W.H., J. Appl. Phys. 53 (1982) 3566-3575.

57. Erlich D.C. \& Chartegnac P., J. Phys. France 46 (1985) Colloq. C5 (DYMAT 85) 455-462.

58. Loizou N. \& Sims R.B., J. Mech. Phys. Solids 1 (1953) 234-243.

59. Baraya G.L., Johnson W. \& Slater R.A.C., Int. J. Mech. Sci. 7 (1965) 621-645.

60. Samanta S.K., Int. J. Mech. Sci. 11 (1969) 433-453.

61. Greenfield M. \& Habib E.T., J. Appl. Phys. 18 (1947) 645-650.

62. Habib E.T., Trans. ASME 70 (J. Appl. Mech. 15) (1948) 248-255. 
63. Bancroft D., Phys. Rev. 59 (1941) 588-593.

64. Prowse W.A., Philos. Mag. (Ser. 7) 22 (1936) 209-239.

65. Shear S.K. \& Focke A.B., Phys. Rev. 57 (1940) 532-537.

66. Redwood M., Proc. Phys. Soc. Lond. B70 (1957) 721-737.

67. Redwood M., J. Acoust. Soc. Amer. 31 (1959) 442-448.

68. Redwood M., "Mechanical Waveguides", publ. Pergamon, Oxford, 1960.

69. Davies R.M., Owen J.D., Edwards D.H. \& Thomas D.E., Proc. R. Soc. Lond. A204 (1950) 17-19.

70. White M.P. \& Griffis L., Trans. ASME 70 (J. Appl. Mech. 15) (1948) 256-260.

71. Carrington W.E. \& Gayler M.L.V., Proc. R. Soc. Lond. A194 (1948) 323-331.

72. Fehr R.O. \& Parker E.R., Proc. Soc. Exptl. Stress Analysis 1 (Part 1) (1943) 76-82.

73. Davies R.M., Phil. Trans. Roy. Soc. Lond. A240 (1948) 375-457.

74. Davies R.M. In "Proc. 7th Int. Cong. on Applied Mechanics: Vol. 1", p. 404, publ. 1948.

75. Graham R.A. \& Ripperger E.A. In "Proc. 4th Midwestern Conference on Solid Mechanics", pp. 382-395, publ. University of Texas, Austin, Texas, 1959.

76. Clausing D.P. In "Proc. 4th Midwestern Conference on Solid Mechanics", pp. 349-357, publ. University of Texas, Austin, Texas, 1959.

77. Hauser F.E., Exper. Mech. 6 (1966) 395-402.

78. Ripperger E.A. In "Proc. First Midwestern Conference on Solid Mechanics", pp. 29-39, publ. University of Illinois, Urbana, Illinois, 1953.

79. Hauser F.E., Simmons J.A. \& Dom J.E. In "Response of Metals to High Velocity Deformation", ed. P.G. Shewmon \& V.F. Zackay, pp. 93-109, publ. Interscience, New York, 1961.

80. Conn J.F., J. Mech. Phys. Solids 13 (1965) 311-327.

81. Malvern L.E., J. Appl. Mech. 18 (1951) 203-208.

82. Campbell W.R., Proc. Soc. Exptl Stress Analysis 10 (Part 1) (1952) 113-124.

83. Campbell J.D., J. Mech. Phys. Solids 1 (1953) 113-123.

84. Ripperger E.A. In "Plasticity (Proc. 2nd Symp. on Naval Structural Mechanics)", ed. E.H. Lee \& P.S. Symonds, pp. 475-487, publ. Pergamon, Oxford, 1960.

85. Rajnak S. \& Hauser F., In "Symposium on Dynamic Behavior of Materials", ASTM STP 336, pp. 167-179, publ. Amer. Soc. Testing Materials, Philadelphia, 1963

86. Davies E.D.H. \& Hunter S.C., J. Mech. Phys. Solids 11 (1963) 155-179.

87. Lindholm U.S., Inst. Phys. Conf. Ser. 21 (1974) 3-21.

88. Tabor D., "The Hardness of Metals", p. 51, publ. Clarendon Press, Oxford, 1951.

89. Gorham D.A., Pope P.H. \& Field J.E., Proc. R. Soc. Lond. A438 (1992) 153-170.

90. Lindholm U.S., J. Mech. Phys. Solids 12 (1964) 317-335.

91. Campbell J.D. \& Duby J., Proc. R. Soc. Lond. A236 (1956) 24-40.

92. Chiddister J.L. \& Malvern L.E., Exper. Mech. 3 (1963) 81-90.

93. Krafft J.M., Sullivan A.M. \& Tipper C.F., Proc. R. Soc. Lond. A221 (1954) 114-127.

94. Follansbee P.S. In "Metals Handbook: Vol. 8 (9th edn.)", pp. 198-203, publ. American Society of Metals, Metals Park, Ohio, 1985.

95. Bell J.F., J. Mech. Phys. Solids 14 (1966) 309-327.

96. Jahsman W.E., Trans. ASME: J. Appl. Mech. 38 (1971) 75-82.

97. Bertholf I.D. \& Karnes C.H., J. Mech. Phys. Solids 23 (1975) 1-19.

98. Briscoe B.J. \& Nosker R.W., Wear 95 (1984) 241-262.

99. Dioh N.N., Leevers P.S. \& Williams J.G., Polymer 34 (1993) 4230-4234.

100. Klepaczko J., Arch. Mech. Stos. 19 (1967) 211-219.

101. Klepaczko J., Mater. Sci. Engng 18 (1975) 121-135.

102. Campbell J.D. \& Briggs T.L., J. Less Common Metals 40 (1975) 235-250.

103. Follansbee P.S. \& Kocks U.F., Acta metall. 36 (1988) 81-93.

104. Kennedy L.W. \& Jones O.E., Trans. ASME: J. Appl. Mech. 36 (1969) 470-478.

105. Gorham D.A., Inst. Phys. Conf. Ser. 47 (1980) 16-24.

106. Safford N.A., "High strain rate studies with the direct impact Hopkinson bar", Cambridge Univ. PhD Thesis, 1988.

107. Sharpe W.N. Jr. \& Hoge K.G., Exper. Mech. 12 (1972) 570-574.

108. Yeung Wye Kong Y.C.T., Parsons B. \& Cole B.N., Inst. Phys. Conf. Ser. 21 (1974) 33-47.

109. Follansbee P.S. \& Frantz C., Trans. ASME: J. Eng. Mater. \& Tech. 105 (1983) 61-66.

110. Gorham D.A., J. Phys. E: Sci. Instrum. 16 (1983) 477-479.

111. Follansbee P.S. In "Metallurgical Applications of Shock Wave and High Strain Rate Phenomena", ed. L.E. Murr, K.P. Staudhammer \& M.A. Meyers, pp. 451-480, publ. Marcel Dekker, New York, 1986. 
112. Safford N.A. In "Proc. 2nd. Int. Symp. on Intense Dynamic Loading and its Effects", ed. ZHANG Guanren \& HUANG Shihui, pp. 378-383, publ. Sichuan University Press, Chengdu, P.R. China, 1992.

113. Gorham D.A., Pope P.H. \& Cox O., Inst. Phys. Conf. Series 70 (1984) 151-158.

114. Walley S.M., Field J.E., Pope P.H. \& Safford N.A., Phil. Trans. R. Soc. Lond. A328 (1989) 1-33.

115. Gorham D.A., J. Phys. IV France 1 (1991) Colloq. C3 (DYMAT 91) 411-418.

116. Harding J., Wood E.O. \& Campbell J.D., J. Mech. Eng. Sci. 2 (1960) 88-96.

117. Duffy J., Campbell J.D. \& Hawley R.H., Trans. ASME: J. Appl. Mech. 38 (1971) 83-91.

118. Lewis J.L. \& Goldsmith W., Rev. Sci. Instrum. 44 (1973) 811-813.

119. Campbell J.D. \& Ferguson W.G., Philos. Mag. 21 (1970) 63-82.

120. Harding J. \& Huddart J., Inst. Phys. Conf. Ser. 47 (1980) 49-61.

121. Ruiz D.J., Harding J. \& Ruiz C., J. Phys. IV France 1 (1991) Colloq. C3 (DYMAT 91) 465-470.

122. Klepaczko J., Inst. Phys. Conf. Ser. 47 (1980) 201-214.

123. Kishida K., Yokoyama T. \& Nakano M., Inst. Phys. Conf. Ser. 70 (1984) 221-228.

124. Bacon C., "Mesure de la tenacité dynamique de matériaux fragiles en flexion-trois-points à haute température - Utilisation des barres de Hopkinson." Thèse de Docteur ès Mécanique, no 840, Univ. de Bordeaux I, 1993.

125. Wasley R.J., Hoge K.G. \& Cast J.C., Rev. Sci. Instrum. 40 (1969) 889-894.

126. Cosculluela A., Cagnoux J. \& Collombet F., J. Phys. IV France 1 (1991) Colloq. C3 (DYMAT 91) 109-116.

127. Lindholm U.S. In "Mechanical Behavior of Materials under Dynamic Loads", ed. U.S. Lindholm, pp. 77-95, publ. Springer-Verlag, Berlin, 1968.

128. Muller T., Acta metall. 19 (1971) 691-699.

129. Eleiche A.M. \& Duffy J., Int. J. Mech. Sci. 17 (1975) 85-95.

130. Rosenberg Z., Dawicke D., Strader E. \& Bless S.J., Exper. Mech. 26 (1986) 275-278.

131. Kishida K., Kataoka T., Yokoyama T. \& Nakano M. In "Macro- and Micro-Mechanics of High Velocity Deformation and Fracture", ed. K. Kawata \& J. Shioiri, pp. 75-84, publ. Springer-Verlag, Berlin, 1987.

132. Maiden C.J. \& Campbell J.D., Philos. Mag. (8th Ser.) 3 (1958) 872-885.

133. Alder J.F. \& Phillips V.A., J. Inst. Metals 83 (1954-55) 80-85.

134. Briggs T.L. \& Campbell J.D., Acta metall. 20 (1972) 711-724.

135. Lindholm U.S. \& Doshi K.D., Trans. ASME: J. Appl. Mech. 32 (1965) 135-142.

136. Francis P.H., Trans. ASME: J. Appl. Mech. 34 (1967) 226-227.

137. Lee T.-C., Trans. ASME: J. Appl. Mech. 41 (1974) 291-293.

138. Campbell J.D. \& Dowling A.R., J. Mech. Phys. Solids 18 (1970) 43-63.

139. Senseny P.E., Duffy J. \& Hawley R.H., Trans. ASME: J. Appl. Mech. 45 (1978) 60-66.

140. Chou S.C., Robertson K.D. \& Rainey J.H., Exper. Mech. 13 (1973) 422-432.

141. Dao K.C. \& Shockey D.A., J. Appl. Phys. 50 (1979) 8244-8246.

142. Lataillade J.L., Marchand A. \& Pouyet J. In "Proc. 9th Intl. Congress on Rheology (Advances in Rheology 3)", ed. B. Mena, A. Garcia-Rejon \& C. Rangel-Nafaile, pp. 137-146, publ. National Free University of Mexico, Mexico City, 1984.

143. Swallowe G.M., Field J.E. \& Horn L.A., J. Mater. Sci. 21 (1986) 4089-4096.

144. Hartley K.A., Duffy J. \& Hawley R.H., J. Mech. Phys. Solids 35 (1987) 283-301.

145. Dawson P.C., Swallowe G.M. \& Xinwu Z., J. Phys. IV France 1 (1991) Colloq. C3 (DYMAT 91) 701-706.

146. Bai Y.L. \& Dodd B., “Adiabatic Shear Localization: Occurrence, Theories and Applications”, publ. Pergamon, Oxford, 1992.

147. Armstrong R.W., Batra R.C., Meyers M.A. \& Wright T.W. (eds.) "Shear Instabilities and Viscoplasticity Theories", Mech. Mater. 17 (1994) 83-327

148. Dorn J.E., Goldberg A. \& Tietz T.E., Trans. AIME 180 (1949) 205-224.

149. Dixon P.R. \& Parry D.J., J. Phys. IV France 1 (1991) Colloq. C3 (DYMAT 91) 85-92.

150. Tugcu P. \& Neale K.W., Int. J. Impact Engng 15 (1994) 41-66.

151. Kumar A. \& Kumble R.G., J. Appl. Phys. 40 (1969) 3475-3480.

152. Follansbee P.S. \& Weertman J., Mech. Mater. 1 (1982) 345-350.

153. Follansbee P.S., Regazzoni G. \& Kocks U.F., Inst. Phys. Conf. Ser. 70 (1984) 71-80.

154. Johnson J.N, \& Tonks D.L., In "Shock Compression of Condensed Matter - 1991", ed. S.C. Schmidt, R.D. Dick, J.W. Forbes \& D.G. Tasker, pp. 371-375, publ. North-Holland, Amsterdam, 1992

155. Gorham D.A., J. Phys. D: Appl. Phys. 24 (1991) 1489-1492.

156. Lindholm U.S. In "High Velocity Deformation of Solids", ed. K. Kawata \& J. Shioiri, pp. 26-35, publ. Springer-Verlag, Berlin, 1978. 
157. Yen C.C.S. \& Yew C.H., J. Materials 4 (1969) 324-337.

158. Hollomon J.H., Trans. AIME 71 (1947) 535-545.

159. Hartley K.A. \& Duffy J., Inst. Phys. Conf. Ser. 70 (1984) 21-30.

160. Klepaczko J.R. In "Impact Loading and Dynamic Behaviour of Materials", ed. C.Y. Chiem, H.-D. Kunze \& L.W. Meyer, pp. 823-830, publ. DGM Informationsgesellschaft mbH, Oberursel, Germany, 1988.

161. Klepaczko J.R., Inst. Phys. Conf. Ser. 102 (1989) 283-298.

162. Behler F.-J. In "Impact Loading and Dynamic Behaviour of Materials", ed. C.Y. Chiem, H.-D. Kunze \& L.W. Meyer, pp. 677-686, publ. DGM Informationsgesellschaft mbH, Oberursel, Germany, 1988.

163. Chiem C.Y. In "Impact Loading and Dynamic Behaviour of Materials", ed. C.Y. Chiem, H.-D. Kunze \& L.W. Meyer, pp. 57-76, publ. DGM Informationsgesellschaft mbH, Oberursel, Germany, 1988.

164. Regazzoni G., Kocks U.F. \& Follansbee P.S., Acta metall. 35 (1987) 2865-2875.

165. Follansbee P.S., Inst. Phys. Conf. Ser. 102 (1989) 213-220.

166. Eleiche A.M. \& Campbell J.D., Exper. Mech. 16 (1976) 281-290.

167. Dioh N., Personal communication. 1994,

168. Armstrong R.W., J. Mech. Phys. Solids 9 (1961) 196-199.

169. Jones I.R., Rev. Sci. Inst. 37 (1966) 1059-1061.

170. Dharan C.K.H. \& Hauser F.E., Exper. Mech. 10 (1970) 370-376.

171. Wingrove A.L., J. Phys E: Sci. Instrum. 4 (1971) 873-875.

172. Wulf G.L. \& Richardson G.T., J. Phys. E: Sci. Instrum. 7 (1974) 167-169.

173. Fong C.W. In "Proc. 3rd Joint TTCP/JTCG Meeting on Explosives", pp. 45-56, publ. Materials Research Laboratories, Australia, 1983.

174. Fong C.W., Propellants, Explosives, Pyrotechnics 10 (1985) 91-96.

175. Walley S.M., Field J.E. \& Palmer S.J.P., Proc. R. Soc. Lond. A438 (1992) 571-583.

176. Walley S.M., Field J.E., Pope P.H. \& Safford N.A., J. Phys. III France 1 (1991) 1889-1925.

177. Staab G.H. \& Gilat A., Exper. Mech. 31 (1991) 232-235.

178. Pope P.H. \& Field J.E., J. Phys. E: Sci. Instrum. 17 (1984) 817-820.

179. Kaye G.W.C. \& Laby T.H., "Tables of Physical and Chemical Constants (14th edn)" pp 31-32, publ. Longman, London, 1973.

180. Nemat-Nasser S., Isaacs J.B. \& Starrett J.E., Proc. R. Soc. Lond. A435 (1991) 371-391.

181. Gerard G. \& Papirno R., Trans. Amer. Soc. Metals 49 (1957) 132-148.

182. Signoret C., Pouyet J.M. \& Lataillade J.L., J. Phys. E: Sci. Instrum. 13 (1980) 1284-1286.

183. Bridgman P.W., "The Physics of High Pressure (3rd edn)", publ. Bell and Sons, London, 1952.

184. McQueen R.P. \& Marsh S.P. J. Appl. Phys. 31 (1960) 1253-1269

185. Yoshida M. \& Thadani N.N. In "Shock Compression of Condensed Matter - 1991", ed. S.C. Schmidt, R.D. Dick, J.W. Forbes \& D.G. Tasker, pp. 585-592, publ. North-Holland, Amsterdam, 1992

186. Davison L. \& Graham R.A. Phys. Rep. 55 (1979) 255-379

187. Wallace D.C. Phys. Rev. B22 (1980) 1477-1486

188. Wallace D.C. Phys. Rev. B22 (1980) 1495-1502

189. Fowles R. \& Williams R.F. J. Appl. Phys. 41 (1970) 360-363

190. Rosenberg Z., Yaziv D. \& Partom Y. J. Appl. Phys. 51 (1980) 3702-3705

191. Rosenberg Z. \& Brar N.S. J. Appl. Phys. (accepted for publication)

192. Graham R.A. \& Reed R.P., Report no. SAND 78-1911, Sandia National Laboratories, Albuquerque, New Mexico, 1978

193. Bauer F. \& Graham R.A. In "Shock Compression of Condensed Matter - 1989" ed. S.C. Schmidt, J.N. Johnson \& L.W. Davison, pp 793-796, publ. North-Holland, Amsterdam, 1990

194. Obara T., Bourne N.K. \& Mebar Y. Submitted to Meas. Sci. Technol.

195. Barker L.M. \& Hollenbach R.E. J. Appl. Phys. 43 (1972) 4669-4675

196. Abou-Sayed A.S., Clifton R.J. \& Herman L. Exper. Mech. 16 (1976) 127-132

197. Espinosa H.D., Raiser G., Clifton R.J. \& Ortiz M. J. Appl. Phys. 72 (1992) 3451-3457

198. Bourne N.K., Rosenberg Z., Mebar Y., Obara T. \& Field J.E. Submitted to "DYMAT 94"

199. Gust W.H. \& Royce E.B. J. Appl. Phys. 42 (1971) 276-295

200. Gust W.H., Holt A.C. \& Royce E.B. J. Appl. Phys. 44 (1973) 550-560.

201. Munson D.E. \& Lawrence R.J. J. Appl. Phys. 50 (1979) 6272-6282

202. Kipp M.E. \& Grady D.E. In "Shock Compression of Condensed Matter - 1991", ed. S.C. Schmidt, R.D. Dick, J.W. Forbes \& D.G. Tasker, pp. 459-462, publ. North-Holland, Amsterdam, 1992

203. Gray G.T. II. In "Shock Waves in Condensed Matter - 1989", ed. S.C. Schmidt, J.N. Johnson \& L.W. Davison, pp 407-414, publ. North-Holland, Amsterdam, 1990 
204. Kumar P. \& Clifton R.J. J. Appl. Phys. 48 (1977) 4850-4852

205. Longy F. \& Cagnoux J. J. Amer. Ceram. Soc. 72 (1989) 971-979

206. Bourne N.K., Rosenberg Z., Crouch I.G. \& Field J.E. To be published in "Shock Waves in Condensed Matter - 1993"

207. Bourne N.K., Rosenberg Z., Crouch I.G. \& Field J.E. Proc. R. Soc. Lond. A (accepted for publication)

208. Bourne N.K., Rosenberg Z., Field J.E. \& Crouch I.G. Submitted to "DYMAT 94"

209. Horii H. \& Nemat-Nasser S. Phil. Trans. R. Soc. Lond. A319 (1986) 337-374

210. Ashby M.F. \& Hallam S.D. Acta metall. 34 (1986) 497-510

211. Johnson J.R. \& Holmquist T.J. In "Shock Wave and High Strain Rate Phenomena in Materials", ed. M.A. Meyers, L.E. Murr \& K.P. Staudhammer, pp 1075-1081, publ. Marcel Dekker, New York, 1992

212. Rosenberg Z. J. Appl. Phys. 75 (1993) $752-753$

213. Rosenberg Z. Submitted to J. Appl. Phys.

214. Brar N.S., Rosenberg Z. \& Bless S.J. J. Phys. IV France 1 (1991) Colloq. C3 (DYMAT 91) 639-644

215. Kanel G.I., Rasorenov S.V. \& Fortov V.E. In "Shock Compression of Condensed Matter- 1991", ed. S.C. Schmidt, R.D. Dick, J.W. Forbes \& D.G. Tasker, pp 451-454, publ. North-Holland, Amsterdam, 1992

216. "Handbook on Experimental Mechanics", ed. A. S. Kobayashi, publ. Prentice-Hall, Eaglewood Cliffs, New Jersey, 1987.

217. Wells A.A. \& Post D. Proc. Soc. Exptl. Stress Analysis 16 (Part 1) (1958) 69-96.

218. Shukla A., Sadd M.H. \& Mei H. Exper. Mech. 30 (1990) 377-381.

219. Manogg P., "Anwendungen der Schattenoptik zur Untersuchung des Zerreissvorgags von Platten," $\mathrm{PhD}$ thesis, University of Freiburg (1964).

220. Theocaris P.S. \& Gdoutos E. Trans. ASME: J. Appl. Mech. 39 (1972) 91-97

221. Kalthoff J.F. In "Handbook on Experimental Mechanics", ed. A. S. Kobayashi, pp 430-500, publ. Prentice-Hall, Eaglewood Cliffs, New Jersey, 1987.

222. Zehnder A.T. \& Rosakis A.J. Int. J. Fract. 43 (1990) 271-285

223. Deason V.A., Epstein J.S. \& Abdallah M. Optics and Lasers in Engineering 12 (1991) 173-187.

224. Arakawa K., Drinnon R.H., Kosai M. \& Kobayashi A.S. Exper. Mech. 31 (1991) 306-309.

225. Whitworth M.B. \& Huntley J.M. Opt. Engng. 33 (1994) 924-931.

226. Huntley J.M. Appl. Opt. 28 (1989) 4316-4322.

227. Huntley J.M. \& Field J.E. Opt. Engng. 33 (1994) 1700-1707.

228. Huntley J.M. \& Benckert L.R. Optics and Lasers in Engineering 19 (1993) 299-312.

229. Fällström K.-E., Gustavsson H., Molin N.-E. \& Wåhlin A. Exper. Mech. 29 (1989) 378-387.

230. Tippur H.V., Krishnaswamy S. \& Rosakis A.J., Int. J. Fracture 48 (1991) 193-204. 